What are teens doing with YouTube? Practices, uses and metaphors of the most popular audio-visual platform

Fernanda Pires ${ }^{1}$, Maria-Jose Masanet ${ }^{2} \&$ Carlos A. Scolari ${ }^{3}$

${ }^{13}$ Department of Communication, Universitat Pompeu Fabra-Barcelona, Spain

${ }^{2}$ Serra Húnter Fellow. Department of Library and Information Science and Audiovisual Communication, Universitat de Barcelona, Barcelona, Spain

Fernanda Pires, Maria-Jose Masanet \& Carlos A. Scolari (2019): What are teens doing with YouTube? Practices, uses and metaphors of the most popular audio-visual platform, Information, Communication \& Society, DOI: 10.1080/1369118X.2019.1672766

To link to this article: https://doi.org/10.1080/1369118X.2019.1672766 
Provide short biographical notes on all contributors here if the journal requires them.

Fernanda Pires (corresponding author)

Universitat Pompeu Fabra

Department of Communication

C/ Roc Boronat, 138 | 08018

Barcelona, Spain

fernanda.pires@upf.edu

ORCID: 0000-0001-6172-7594

Fernanda Pires has a postdoctoral Juan de la Cierva fellowship at the MEDIUM research group in the Department of Communication of Universitat Pompeu FabraBarcelona. She holds a PhD in Information and Knowledge Society from the Open University of Catalonia. Her main research interests include co-viewing, UGC, social media, media literacy, social practices and popular culture.

Maria-Jose Masanet

Universitat de Barcelona

Department of Library and Information Science and Audiovisual Communication

C/ Melcior de Palau, 140| 08014

Barcelona, Spain

mjose.masanet@ub.edu

ORCID: 0000-0002-1217-9840

@mj masanet

Maria-Jose Masanet is a tenure-eligible lecturer from the Serra Húnter programme at the Department of Library and Information Science and Audiovisual Communication of the Universitat de Barcelona. Her research interests are media literacy, adolescence and youth, TV series and gender. She has been a visiting researcher at Loughborough University (2013) and Université Sorbonne Nouvelle (2015).

Carlos A. Scolari

Universitat Pompeu Fabra

Department of Communication

C/ Roc Boronat, 138 | 08018

Barcelona, Spain

carlosalberto.scolari@upf.edu

ORCID: 0000-0002-7792-0345

Carlos A Scolari is an associate professor at the Department of Communication (Universitat Pompeu Fabra-Barcelona, Spain), Principal Investigator of the Transmedia Literacy Research Project (EU-H2020-RIA, 2015-18), and coordinator of the PhD Programme in Communication at UPF. He is an expert in transmedia storytelling, digital interactive media, and media ecology. 


\title{
What are teens doing with YouTube? Practices, uses and metaphors of the most popular audio-visual platform
}

\author{
This article is part of the outcomes of the Transmedia Literacy research project \\ on teens and transmedia collaborative practices carried out in eight countries \\ between 2015 and 2018. A multi-method approach was used in the study \\ (questionnaires, workshops, media diaries, interviews, observation of online \\ communities) to explore what teens are doing with media. This article presents a \\ map of the uses and practices teens make of YouTube. The metaphors of \\ YouTube that emerged when teens put these uses and practices into discourse are \\ also identified. Five YouTube uses were detected: radiophonic, televisual, social, \\ productive and educative. These uses vary according to the practices performed \\ by teens and how they are related to the logics of the YouTube platform. \\ Moreover, the identified metaphors show the ways teens' uses are related to their \\ everyday routines and the way they integrate the YouTube platform into various \\ dimensions of their social life, such as their media practices, and the way they \\ acquire knowledge and skills.
}

Keywords: YouTube, teenagers, uses, practices, metaphors, platforms

\section{Introduction}

Since its creation in 2005, YouTube has been one of the most disruptive platforms of the media ecology. YouTube has become one of the world's largest platforms for accessing, searching, watching, sharing and creating video contents, among other specific uses given to it by its users. With more than 1.9 M monthly users (YouTube, 2019), it plays a leading role in the new media ecology largely due to its ability to reinvent itself over time. It was launched as an independent platform for ordinary people to upload videos; the following year it was purchased by Google. The main evolutionary steps that YouTube took as part of the Alphabet Inc. meta-platform include the introduction of recommendation-filtering algorithms for suggesting content, the creation of 'channels' and the launching of its Premium subscription, YouTube Music 
and YouTube Kids. According to van Dijck (2013)

YouTube did not really invent video sharing as a sociotechnical practice, and neither did it revolutionize broadcast technology. Contrary to public image, Google pushed professional content at an early stage, and its innovative online strategies soon merged with conventional broadcast tactics (p. 111).

YouTube's evolutionary process has not only been marked by technological changes, but also by a clear interplay with users and their practices within the platform. According to Burgess and Green (2018), each YouTube group of contributors and participants has collectively shaped the platform as a cultural system. Teens are one of the groups of users that continues to grow worldwide and thus deserves research attention (Bucher, 2018; Caron et al., 2017).

This article comes from a research study on teens and transmedia collaborative practices carried out in eight countries between 2015 and 2018. The aims of the research were to understand what teens are doing with media and how they are learning to do it. In order to answer these questions, the research team identified and analysed teens' transmedia practices and the main informal learning strategies they apply in everyday life. This article focuses on the main outputs related to the uses teens make of YouTube. YouTube occupies a central role in the media life of teens (Ito et al., 2010; boyd, 2014; Pereira, Moura, \& Fillol, 2018). During the data-gathering phase of the research, it was clear that teens could approach the platform as either consumers and/or producers. YouTube is a key space of their media diet and, in some cases, is their main source of information. YouTube, more than Google, is for many teens the main search engine. It is a platform that offers teens not only entertainment but also generates a sense of community. Within this framework, for many teens YouTubers have become aspirational models they can identify with (Aran-Ramspott, Fedele, \& Tarragó, 2018; Scolari \& Fraticelli, 2017). Teenagers even claim to want to become YouTubers in the 
future, and consider it a profession (Establés, Guerrero-Pico, \& Contreras-Espinosa, 2019).

Taking into account the important role YouTube plays for teens, it is necessary to explore the uses, practices and understandings they give to it. In a time when multiple instances of social life are expressed and conditioned by digital media and platforms, by looking at media practices it is possible to better understand the unique social processes that are enacted through them (Couldry, 2012), and which use artefacts, technologies and their architectures.

To complete the study of teens' YouTube uses and practices, the article analyses the YouTube metaphors that teens apply in their discourses about the platform. From a cognitive approach, metaphors are not just a way of enriching the language but a powerful tool for understanding new phenomena and thinking about them (Lakoff \& Johnson, 1980). According to Reimer and Camp (2008) “what we would normally classify as metaphorical language should, on this view, be analyzed instead as a direct, explicit representation of a metaphorical way of thinking" (p. 859). To identify and analyse teens' metaphors of YouTube is another way of reconstructing what they think about the platform and how they use it.

Therefore, the main objectives of the article are:

- To present a map of the most relevant teen YouTube uses and practices;

- To identify, describe and analyse the most relevant metaphors of YouTube detected in teens' discourses.

Studying teens' transmedia collaborative practices and uses within a platform like YouTube offers a universe of possibilities for understanding these social phenomena. Therefore, the following section reflects on the basic concepts behind the 
present article: practices, uses and metaphors.

\section{Practices, Uses and Metaphors}

Following Schatzki (1996) and Warde (2005), practices can be interpreted in two different, but complementary, ways: a) the practice as a coordinated entity; b) and the practice as performance. The practice-as-entity refers to the ways a practice is organized and takes shape. Thus, a practice must have an organization, certain rules that should be understood by practitioners to perform the practice. Nonetheless, subjects perform a practice based on their aims, emotions, projections, and motivations.

The practice-as-performance refers to the enactment of a practice. It is by the performance that a practice is sustained, updated or ceases. For a practice to be alive it must be re-enacted (Shatzki, 1996). Thus, time can be an essential element of practiceas-performance because timing, sequencing, and scheduling are factors for carrying out a practice or prefiguring it (Shove, Pantzar \& Watson, 2012). Moreover, for a practice to be performed it is necessary to have practitioners who carry out the practice in various ways and transform it over time (Hui, Schatzki \& Shove, 2017). Thus, practices are not static; rather, practices "contain the seeds of constant change. They are dynamic by virtue of their own internal logic of operation, as people in myriad situations adapt, improvise and experiment" (Warde, 2005, p.141) with the available resources and also due to the different uses and technologies attributed to them.

Regarding the relationship between practice and language, according to Barker (2004):

A practice is a way of doing things, an action, application or performance that occurs as a consequence of intention, habit or routine (...) While the metaphor of culture as 'like a language' has a great deal to recommend it, it is not sound 
thinking to allow language to be separated off from practices since language is always embedded in practice (p.163).

Similarly, Schatzki (1996) considers that practices are constituted by doings and sayings, so language and meaning cannot be dissociated from practices as they are manifested through bodily/mind types of behaviours.

The concept of 'practice' has been defined from a cultural theory perspective from the second wave of practice theorists (Reckwitz, 2002; Postill, 2010), and the concept of 'use' will be approached from a perspective inspired by the works of the Latin-American cultural school (Martín-Barbero, 1993; García-Canclini, 2005). According to Martín-Barbero (1993):

Consumption is not just the reproduction of forces. It is a production of meanings and the site of a struggle that does not end with the possession of the object but extends to the uses, giving objects a social form in which are registered the demands and forms of action of different cultural competencies (p. 214).

Martín-Barbero proposed an analysis of the logics (plural) of uses that goes beyond traditional approaches (like the theory of uses and gratifications) and put the study of reception into the field of culture. Regarding traditional TV reception, Martín-Barbero said that

There are uses that are not only a question of the amount of time spent watching television but the type and social significance of the time and of the demands that different social classes place on time spent watching television (...) (However) The different uses of television are not only a question of social class. Also important is the cultural competence of the groups (p. 222).

Obviously, the same approach can be applied to contemporary (new) media viewing practices, for example watching or sharing videos on YouTube. 
If practices are constituted by doings and sayings, then the analysis of the discourses - in this case, the analysis of the YouTube metaphors - should not be excluded from the research. A long series of researchers have demonstrated that metaphors are more than a poetic ornament of language: they are basic rhetorical devices of human language and communication (Ortony, 1979; Lakoff \& Johnson, 1980). Metaphors are very useful for giving a sense to new experiences that are otherwise almost impossible to interpret; at the same time, they are useful for generating categories, organizing processes and establishing oppositions and hierarchies. The metaphor provides speakers with a model for understanding a new territory, offering a conception and a set of words to talk about it. At the same time, the metaphor facilitates the transmission of a new concept to other people. In this context, the article will analyse how teens metaphorize YouTube when they talk about it.

\section{Methodology}

This article is one of the outcomes of broader research about teens, media and collaborative cultures (Scolari, 2018). The research followed a qualitative approach based on the precepts of short-term ethnography (Pink \& Morgan, 2013). The ethnographic approach has been shown to be a reliable and well-established methodology for studies in different fields, such as education (i.e. Street, 2014), youth and new media (i.e. Livingstone \& Sefton-Green, 2016). Short-term ethnography gives the researcher the opportunity to gather data within a shorter time period compared to traditional ethnography. Given the geographical extension of the research (Australia, Italy, Portugal, Spain, United Kingdom, Finland, Uruguay, and Colombia) and the difficulties involved in working with different school settings and socio-educational environments, this methodology was suitable for creating contexts in which researchers could go deeper into research questions in a brief and intense period of time. 
During the fieldwork, the team implemented a more interventional creative approach (traditional focus groups were substituted by creative workshops) as well as observational methods for creating meaningful research contexts in which participants can become involved (Pink \& Morgan, 2013).

The research was carried out through the following procedure:

(1) Ethical and data management protocols (consents of schools, parents and teens);

(2) 1,633 questionnaires about teens' socio-cultural backgrounds and their media access, habits, uses and perceptions;

(3) Fifty-eight creative participatory workshops to immerse the researchers and explore the media practices and universes of adolescents. These workshops worked on three specific areas: participatory culture, videogames and social media;

(4) 311 in-depth interviews and 90 media diaries were carried out to deepen discourses about the teens' media practices;

(5) Online observation of eight websites, media celebrities, and online communities followed by teens.

Teens (11-19 years) from eight countries participated in this research as shown in Figure 1. 


\begin{tabular}{|c|c|c|c|c|c|}
\hline \multirow[b]{2}{*}{ Country } & & \multicolumn{3}{|c|}{ Age } & \multirow[b]{2}{*}{ Total } \\
\hline & & 11-14 & 15-19 & $\mathrm{N} / \mathrm{A}$ & \\
\hline \multirow[t]{4}{*}{ Spain } & Male & 21 & 29 & 0 & 50 \\
\hline & Female & 21 & 27 & 1 & 49 \\
\hline & N/A & 1 & 0 & 0 & 1 \\
\hline & Total & 43 & 56 & 1 & 100 \\
\hline \multirow[t]{4}{*}{ Portugal } & Male & 15 & 16 & 0 & 31 \\
\hline & Female & 20 & 26 & 0 & 46 \\
\hline & N/A & 0 & 0 & 0 & 0 \\
\hline & Total & 35 & 42 & 0 & 77 \\
\hline \multirow[t]{4}{*}{ Italy } & Male & 24 & 33 & 0 & 57 \\
\hline & Female & 19 & 21 & 0 & 40 \\
\hline & N/A & 0 & 0 & 0 & 0 \\
\hline & Total & 43 & 54 & 0 & 97 \\
\hline \multirow[t]{4}{*}{ Finland } & Male & 18 & 23 & 0 & 41 \\
\hline & Female & 11 & 21 & 0 & 32 \\
\hline & N/A & 0 & 1 & 0 & 1 \\
\hline & Total & 29 & 45 & 0 & 74 \\
\hline \multirow[t]{4}{*}{ UK } & Male & 29 & 27 & 0 & 56 \\
\hline & Female & 30 & 19 & 0 & 49 \\
\hline & N/A & 0 & 0 & 8 & 8 \\
\hline & Total & 59 & 46 & 8 & 113 \\
\hline \multirow[t]{4}{*}{ Australia } & Male & 287 & 213 & 3 & 503 \\
\hline & Female & 202 & 143 & 3 & 348 \\
\hline & N/A & 1 & 8 & 0 & 9 \\
\hline & Total & 490 & 364 & 6 & 860 \\
\hline \multirow[t]{4}{*}{ Uruguay } & Male & 24 & 14 & 0 & 38 \\
\hline & Female & 10 & 17 & 0 & 27 \\
\hline & N/A & 0 & 2 & 0 & 2 \\
\hline & Total & 34 & 33 & 0 & 67 \\
\hline \multirow[t]{4}{*}{ Colombia } & Male & 47 & 78 & 0 & 125 \\
\hline & Female & 44 & 75 & 0 & 119 \\
\hline & N/A & 1 & 0 & 0 & 1 \\
\hline & Total & 92 & 153 & 0 & 245 \\
\hline Total & & 766 & 747 & 7 & 1633 \\
\hline
\end{tabular}

Figure 1: Sample Distribution by Country. Source: Authors' own elaboration.

Between two and four schools were involved in each country depending on the different educational systems. This article focuses on the results from all of the countries and analyses the data derived from the workshops, interviews, and media diaries. It focuses exclusively on the results related to the teenagers' use of YouTube, as 
this platform was one of the most popular that teenagers used in their day-to-day life. This methodology was tested in Barcelona in the second semester of 2015, and the fieldwork was carried out during the first semester of 2016.

The data was processed during 2017 and 2018. The research team used the software NVivo 11 Pro for teams to carry out an inductive and interpretative data analysis.

In the Results section all the names used in the teens' quotes are pseudonyms. The authors translated the quotes into English, which further prevented recognition.

\section{Results}

To facilitate the interpretation of the main analysis outcomes, this section opens with a table summarizing YouTube uses, practices and metaphors. Table 1. shows the recurrent activities carried out with YouTube, classified into five basic uses: radiophonic, televisual, social, productive and educative. Each use includes a series of practices that characterizes them. These uses sometimes overlap and have similar characteristics because of the way the YouTube architectures prefigure the way they are materialized. Therefore, some YouTube metaphors that were detected were unique, while others were transversal to different uses and practices. 


\begin{tabular}{|c|c|c|}
\hline Uses & Practices & YouTube metaphors \\
\hline Radiophonic & $\begin{array}{l}\text { - } \text { Listen to music as a } \\
\text { background during } \\
\text { multitasking; } \\
\text { - } \quad \text { Find new songs; } \\
\text { - } \quad \text { Archive or collect music; } \\
\text { - } \quad \text { Download music. }\end{array}$ & $\begin{array}{l}\text { - } \text { Companion; } \\
\text { - } \text { Radio programmer; } \\
\text { - Search engine; } \\
\text { - Repository; } \\
\text { - Archive; } \\
\text { - } \quad \text { Library. }\end{array}$ \\
\hline Televisual & $\begin{array}{l}\text { - Watch entertainment } \\
\text { content; } \\
\text { - Get up-to-date; } \\
\text { - Be informed; } \\
\text { - Jump window releases; } \\
\text { - Follow YouTubers and } \\
\text { celebrities. }\end{array}$ & $\begin{array}{ll}\text { - } & \text { Smart TV; } \\
\text { - } & \text { Repository; } \\
\text { - } & \text { Information medium; } \\
\text { - } & \text { Search engine; } \\
\text { - } & \text { TV programmer; } \\
\text { - } & \text { Celebrity system. }\end{array}$ \\
\hline Productive & $\begin{array}{l}\text { - Create and/or manage } \\
\text { personal content. }\end{array}$ & $\begin{array}{l}\text { - } \text { Distribution channel; } \\
\text { - Celebrity system; } \\
\text { - Meritocratic system. }\end{array}$ \\
\hline Social & $\begin{array}{l}\text { - Co-produce; } \\
\text { - Obtain social recognition; } \\
\text { - Comment; } \\
\text { - Co-view. }\end{array}$ & $\begin{array}{ll}\text { - } & \text { Co-creation space; } \\
\text { - } & \text { Feedback tool; } \\
\text { - } & \text { Digital 'living room'. }\end{array}$ \\
\hline Educative & $\begin{array}{l}\text { - } \quad \text { Learn by doing; } \\
\text { - } \quad \text { Solve problems; } \\
\text { - } \quad \text { Learn something new; } \\
\text { - Answer questions. }\end{array}$ & $\begin{array}{ll}\text { - } & \text { MOOC; } \\
\text { - Informal learning space; } \\
\text { - Search engine; } \\
\text { - Tutorial Repository. }\end{array}$ \\
\hline
\end{tabular}

Table 1. Teens' YouTube uses, practices and metaphors. Source: Authors' own elaboration. 


\section{Radiophonic Use}

Many teens state that listening to music is one of the leading uses of YouTube. Because this practice resembles the traditional practice of listening to radio broadcasting devices, this set of activities will be considered as part of the radiophonic use of the platform.

The most recurrent routine practice that emerged in the teens' media diaries was to listen to music on YouTube while doing other activities: "I woke up and turned on my mobile phone to connect with my Smart TV and listened to music on YouTube while I was making my bed" (Alejandro, male, 15-years-old, Colombia).

Listening to music appeared as a practice that is part of their daily routine, when they are getting ready to go to school for example. A similar routine was once part of the radiophonic related activities, since people tended to listen to music in varied contexts that were often mobile (Gutiérrez, 2008). This mobility comes from the portability of the radio (Carroll et al., 1993) and the later forms of listening devices, such as the Walkman, MP3 player, iPod, and, nowadays smartphones and other devices, which can connect to platforms such as YouTube. Thus, it was no surprise that some teens listened to YouTube in the car or when they were walking.

As teens combine this practice with other activities, the YouTube metaphor is that of a companion. This practice can be associated with the radio that provided companionship while people were doing practices not related to music, such as driving, cleaning the home, etc. This conception can be traced back to the end of the 1960s in the study of Troldahl and Skolnik (1968), where the authors identified that the radio was keeping teens company and making the time go faster while they did other activities. Following an ecological metaphor, the listening practices do not compete with other activities, rather they are part of a context that involves an interweaving of different 
practices (Shove, Pantzar, \& Watson, 2012) that, combined, define a specific pattern of the teens' daily life.

This radiophonic use was reinvented in the YouTube platform. However, until recently this feature of background music could only be used by having the website open on the computer, or the app open in a smart device without locking the screen. Once the screen was locked, the songs would stop playing. With the YouTube Premium (2015) and YouTube Music (2018) paid subscriptions, background listening was incorporated into the platform. Although these paid subscriptions exist, teens still listen to music without paying, accepting the limitations imposed by the free version of YouTube.

For teens, YouTube is also a medium that selects what listeners should listen to. Instead of the traditional radio professional who programs the content, YouTube's algorithms now play this role and suggest content to YouTube users (van Dijck, 2013). The platform is perceived as a facilitator that identifies songs and playlists: "I rarely search for music, YouTube has this page where it's just recommendations...It makes it easier instead of going to search" (Leslie, female, 17-years-old, Australia).

Although YouTube was not initially designed to work like a radio programmer, this deviated use was implemented by the users and helped to reshape it. Moreover, this radiophonic use of YouTube remits to a post-broadcasting form of music mediatization. In other words, a series of practices and uses from other devices - in this case the broadcasting radio - were transferred to the logic of networking, and they became “platformized” (Fernández, 2018).

The research team also found teens who perform a more active usage of YouTube. They use the platform for listening to music in four different ways that can be 
interpreted under four YouTube metaphors: as a search engine, as a repository, as an archive, and as a library.

When YouTube works as a search engine, teens use the platform to find songs: “(...)I usually listen to music based on Italian rankings, then if I want to listen to a particular song I search for it on Youtube" (Giulia, female, 17-years-old, Italy).

Most of those searches were motivated by a personal interest in finding a particular song. This kind of search was also supported and channelled by other features of the YouTube interface that go beyond the search engine and involve using other automatized features, such as the YouTube recommendation system: "For example if I hear a song around, I search for it on YouTube, if I don't find it I look at the related videos [recommended by YouTube] to see if I find it or find other songs" (Francesca, female, 17-years-old, Italy). The YouTube features are also used by teens when they search actively, as they are driven by their desire to increase awareness of songs.

Moreover, teens use the platform as an online archive to store their music collection in their account: "I have a YouTube account, but I don't post anything. It's just, like, I keep the videos I like there, and all the music I like" (Leslie, female, 17years-old, Australia). These practices are also long-standing practices that were historically associated with the physical qualities of material goods, such as tape collections recorded from the radio, or original record collections. Now the logic of collecting practices is applied to digital goods, which are often treated by scholars as information rather than objects (Steirer, 2014). In this study, these practices are revamped by teens who make YouTube their own digital database, where they can store their songs as their personal collectible objects.

Another metaphor teens give to YouTube is similar to its first slogan (YouTube your personal repository!). In this context teens can find all the music in a varied range 
of languages in comparison with other music platforms like Spotify: "I like Portuguese Hip Hop, and there are not many artists in Spotify, only the most famous, so I tend to go to YouTube" (Nuno, male, 16-years-old, Portugal).

Teens use YouTube as a library for downloading songs and copying and pasting YouTube's hyperlinks in non-official YouTube converter and downloader websites: “I've also downloaded some MP3s through YouTube. I don't want anything that costs"(Jarkko, male, 17-years-old, Finland).

Teens do not agree with paying for contents that in their eyes is already free on the platform. Because of practices like these, YouTube is often mistaken for a peer-topeer file-sharing platform (van Dijck, 2013).

That YouTube would be used as a music library was initially not planned by the company, but as downloading became so popular it was incorporated by the Alphabet corporation in the YouTube Music App paid subscription, which allows users to download music and listen to it offline. Thus, the sense of the technology emerges from a negotiation process between the different actors involved in the socio-technological network.

\section{Televisual Use}

Teens use YouTube for watching videos and this practice is part of the televisual use of YouTube. As with the radiophonic use, teens adapt practices originally developed in the context of television broadcasting to new interactive and social platforms.

Although YouTube is still well-known as a platform for user-generated content, since its purchase by Google in 2006 the company has oriented itself towards becoming a platform that prompts professionally generated content with an ad-friendly environment (Kim, 2012). Moreover, it has implemented a monetization system that 
regulates copyright and encourages television networks to use YouTube as another distribution channel of broadcast formats, and a space to release short formats that are typical of the platform itself (van Dijck, 2013). Not surprisingly, the research team detected that teens use YouTube for watching traditional television contents. Facundo, a 13-years-old male from Uruguay, consumes a TV series on YouTube that is produced and aired by the Argentinian network Telefe: "Now I am addicted to a TV series that is called Aliados (...) To watch it, I connect my mobile to the TV, because it's also available on YouTube".

Because of smart TV technologies, such as mirroring, teens can transform YouTube into their TV, but using it with the convenience of streaming: "On YouTube, I like to watch the programs like American Horror Story, which is a television series. I follow it on my iPad. I follow like this because I can see it at the time I want, and if I need to, I can pause" (Francesca, female, 17-years-old, Italy).

Catching-up is another complex practice that involves the articulation of many intertwined experiences (Couldry, 2012). Therefore, the way teens can seamlessly embed media consumption into their everyday routines can happen only by catching-up with the flow of various media texts that are spread on YouTube. As an example, teens continue watching products of broadcast television, but in many instances, they cannot watch it in the scheduled time because they are doing other activities. Thus, teens use YouTube for catching-up with a lost episode: "Sometimes I go on YouTube to search for the weekly episodes of a TV series that I couldn't watch" (Nuria, female, 17-yearsold, Spain). Moreover, teens look at summaries of TV shows or highlights of a game match, usually due to a lack of time. Once again, YouTube serves them as their repository, as they can retrieve what they have missed by searching for it. YouTube also works as a digital space where teens can go to get up-to-date with live broadcast events 
that break the broadcast routine (Katz, 1980), such as sport events: "I watch a lot of basketball. Because I don't have enough time to watch the full game, I just watch highlights" (John, male, 13-years-old, Australia).

Time is also a dimension that interweaves with another practice that is grounded in the broadcasting model: the practice of skipping the windowing strategies of television distribution. Windowing is a process of maximizing profit when content is released in a determined time and sequence in different countries and regions (Doyle, 2016). This classic strategy has always been marked by the delay that viewers might experience in watching their favourite content that may arrive months or years later in a different country from the one where it was first released. These issues have led broadcast content to be subjected to piracy.

In this case, teens use YouTube as a search engine to find their favourite TV programs. The source of these programs on YouTube does not matter to the teenagers. What matters is to watch their show: "When I watch a series, I look to see if there's a next season on YouTube because it takes a long time for them to translate it into Spanish[...] So I look to see if it's available" (Carmen, female, 13-years-old, Spain).

This craving for novelty is also visible in the YouTube content that is not necessarily created by professionals. The same way teens try to find new songs, they search for videos that fit their personal interests, e.g. gameplays. They also rely on the platform as a television programmer by taking into account the YouTube recommendation system.

Another practice is to keep up with news. Teens may use YouTube more actively, searching "for news to get informed about what is happening around the world and in the country" (Javier, male, 16-years-old, Colombia) and about a specific topic of their interest, but they also use it passively, by just following the recommendations of 
the algorithms. This is how Juan, a 14-years-old male from Colombia, found out when the Capitan America movie would be released: "the page already knows what you like and the important things appear".

Teens also select what they would watch based on the YouTube advertisement system: “On YouTube, I watch walk-throughs of games, and I just skim through channels and come across them, or I've seen them advertised on YouTube" (Dan, male, 14-years-old, UK).

YouTube's mass media revenue system corresponds to a growing professionalization of amateurs and the rise of YouTube celebrities. Although they show an amateur aesthetic, they fall into the traditional mass media celebrity system (Scolari \& Fraticelli, 2017). Hence, another detected practice was to follow YouTube celebrities.

Teens watch this new kind of celebrity, such as YouTubers, because they identify with them as they have a similar age, taste, aims, and perform similar practices (i.e. gameplays). Furthermore, teens follow YouTubers and channels due to two important aspects: they can have fun and also learn with them. This is independent of the content and is because YouTubers give tips and share experiences that most of the teens can apply in their routines (Scolari, 2018).

\section{Productive Use}

The research team found many teens that take photos and create videos in their daily life but few of them share these contents on YouTube. The team found that the teens' productive use includes creation of videos for YouTube that are 'aspirational' (of being professional) and 'expert'. They usually have production, narrative and aesthetic skills and produce with the aim of reaching broader audiences (Guerrero-Pico, Masanet, \& 
Scolari, 2019).

One of the metaphors teens apply to YouTube is the metaphor of a distribution channel, a place to make their own creations public. Most YouTube content producers detected in the study were male, and their creations were mainly gameplays. There are also exceptions, for example teens that produce videos explaining their own life experiences: "I used to tell my stories on this channel, my experiences, and like all gamers I used to do it while playing” (Lucia, female, 14-years-old, Colombia).

Few teens claim to seek 'fame' on YouTube. On the contrary, practically all of them explain that their goal is more 'social', as they seek to help people and friends with their videos. Nonetheless, in most cases they end up talking about their followers and the projection of their creations. This shows a marked interest in achieving visibility and popularity on YouTube. In this context, YouTube emerges as a celebrity system and this metaphor appears in the teens' discourses. This is the case of Rathelos, a 15-yearold boy from Australia who starts by explaining that he produced a video about a game to help people but then goes on to talk about the number of views his video received: "I made a video about it to help people, and I got 300 views for that. I think that was the most views I got for a video". Rathelos ends up talking about the visibility that YouTube can give him and compares it with other spaces where he could share his work: "At that time a lot of people used YouTube, like over four billion people, so it's better to upload on YouTube than just put it on a website". In the same line, a teen that is already inserted in the YouTube celebrity system speaks about their audience like a famous person: 'But now that I have some subscribers in YouTube, I do the videos for them. I have something like 1,800 subscribers" (Timo, male, 16-years-old, Finland).

In these cases (which are not common) a certain 'professionalization' of these teens can be observed, and they consider YouTube as a work option (Establés, 
Guerrero-Pico and Contreras-Espinosa, 2019). The comments made by Arwyn, a 15year-old boy from the UK, illustrate this. Arwyn talks about strategies for getting followers and explains that he does live streams that last for several hours: "it shows that you're investing in your channel by spending so much time on your channel, so it makes people know that you're actually serious about it'. As it can be seen, teens are aware that there are many 'aspirational' creators who do not become professional or 'expert' producers and that there are strategies for knowing which ones 'are really trying'.

YouTube can be adapted or reconfigured based on the uses given to it by its users. Having said that, it is not surprising that YouTube has created a specific channel for video producers: the Creator's Academy. It is part of the platform's efforts over the past few years to foster the production of original and high-quality content. As a strategic element in YouTube's current set-up, content creators are prized according to the performance of their videos in terms of viewership and subscribers. Depending on the level, they may even have access to production resources. Therefore, being visible to YouTube's search and discovery system is considered an essential element of the creator's practice within the platform content. As the team has observed, most teens who create content for YouTube follow the same logic of the Creator's Academy consciously or unconsciously. Maybe it was not their initial intention when they started producing for YouTube but, over time, they have become immersed in YouTube's logic and have tried to produce quality content that must be unique. Therefore, YouTube can be considered a 'meritocratic system'. Those who do not 'professionalize' or are not being rewarded for their amount of 'views' and 'subscribers' may abandon their production activity or stop sharing their content on YouTube. This is the case of Yash, a 14-year-old boy from Australia, who explains that he makes videos about 'nerf guns' 
and does not upload the videos because he does not consider that they are 'unique' or 'have enough quality': “[...] I haven't uploaded because I don't feel they're unique and I find that you could find much better videos about them on different channels". Yash considers that this is what people are looking for.

\section{Social Use}

In the 'social use' the practices performed by teens with YouTube imply a social interaction rather than a solitary use of the platform. Teens use the platform and its videos for socializing by carrying out different practices: co-producing, sharing content, obtaining social recognition, commenting on the videos in the dedicated space of the platform or in person, and physically co-viewing with other viewers.

First, related to the previous point on production, there are 'social' aspects that surround the processes of creation and sharing. Almost all teens who produce content for YouTube claim to do it for "the others" (the viewers), who are usually their friends or followers. This is the case of Arwyn, the 15-year-old boy from the UK: "I'm only doing it for other people". The act of sharing their creations already implies a social use that is inherent to YouTube and other platforms. This is related to social recognition. As explained in the previous subsection, the projection and social recognition through followers and views is a key aspect when content is created and shared. Some teenagers take it for granted that they will share the content they create. During the break of a workshop in Spain, a group of girls explained about the video they were making to a friend who was not participating in the workshop. He wanted to see the result and asked whether they were going to share it on YouTube. Therefore, it was observed that some teens consider YouTube to be one of the main platforms where teens share their creations, although they are not the majority. 
Another social use related to production is the 'co-creation' practice: "I create a lot of videos together with my brothers and sisters and with my friends" (Vittorio, male, 17-years-old, Italy). Therefore, YouTube is also understood as a co-creation space, where teens like Vittorio learn and enjoy from and with their peers when they co-create something to be shared on the platform.

YouTube also works as a 'feedback tool' when teens write comments. There are many teens that comment on YouTube and have even created their accounts to do specifically that: "I have a channel to comment"(Dario, male, 12-years-old, Uruguay). There are different dynamics when commenting. In some cases, teens do it not only as an assessment of the video content and aesthetics, but also in order to make contributions and recommendations for future videos or improving the current ones. Some teens emphasize that the comments space provided by the platform can also be used to ask for help about certain topics, such as videogames and video editing software.

YouTube may also be understood as a 'digital living room'. Co-viewing is a practice that exists since television first became a household appliance used by family and friends who gathered around this single device to share the experience of watching an event or a TV show. This practice was revamped to connected platforms like YouTube so it could occur beyond the television set (Pires, 2018). This practice can also be considered as part of the televisual use of YouTube; however, since it began to be studied it has been considered a peer phenomenon (McDonald, 1986), and thus it is included as a social use of YouTube. Teens co-view to exchange their impressions about what they are watching, to enjoy and have the company of other peers. Teens had different motivations for co-viewing. The most common co-viewing groups were siblings, friends and school colleagues. For those teens that co-view with friends and 
colleagues the particular interest in videogames was transversal: "I watch videos with my boyfriend on YouTube about games that we play together" (Florbela, female, 15years-old, Portugal). As it can be seen, they co-view contents with which they identify and it is usually also related to a ludic engagement.

\section{Educative Use}

According to Coombs and Ahmed (1974), informal education is "the lifelong process by which every person acquires and accumulates knowledge, skills, attitudes and insights from daily experiences and exposure to the environment" (p. 8). Informal learning is usually integrated with daily routines and triggered by an internal or external jolt; in most of the cases, informal learning is not highly conscious and presents itself as an inductive process of reflection and action influenced by chance. Informal learning may seem individual but it is linked to learning with others (Marsick \& Volpe, 1999, p. 5).

During the research, YouTube emerged as the most important informal learning platform for teens (Scolari, 2018).

Teens use YouTube to learn about different topics, like finding new games or discovering tricks and bugs in the most popular games. In most workshops, the research team observed teens looking for information about videogames on YouTube and teenagers even stated that they use it 'to learn' about videogames. There were also a few teenagers who create content for teaching their classmates. For example, in a workshop in Spain, two boys showed the videos they uploaded on YouTube to teach their friends to get through a videogame level. Then, their classmates asked them to make a video of a specific game and upload it to YouTube to learn how to overcome a certain game situation. Hence, educational use is intertwined with social and productive use. Some teenagers teach, while others learn from these contents. 
But teens also learn about a wide variety of topics ranging from 'how to take care of an animal' to learning 'academic content'. Thus, in some cases, YouTube functions as a MOOC platform: "There are videos teaching you how to do [math] equations. There's a channel of a teacher I follow because it really helps me with maths" (Lucero, female, 14-years-old, Colombia). This happens because teens see YouTube as a free platform where they can literally find any kind of content, working as a tutorial repository: "YouTube is the perfect page for tutorials, because tutorials of everything you can possibly look for are uploaded there" (Manuel, male, 16-years-old, Spain).

It can be seen how teens rely on YouTube as a search engine for finding learning content. In most cases, they go directly to YouTube and not to Google: "YouTube magic starts when I search for tips on how to learn to play [videogames] " (Felix, male, 16-years-old, Portugal). In the research context, these teens were defined as 'digital apprentices', that is, “young people who have been born and raised in a media environment that has provided them with a digital space for learning [...] In this virtual space they can find answers to their questions based on their practices and media uses [...]. They follow traditional models such as 'imitation' (learning by doing) and 'learning by teaching' but in new spaces (mainly virtual) and with new actors (peers, influencers, etc.)" (Masanet, Guerrero-Pico, \& Establés, 2019). Therefore, YouTube is the 'natural' environment for online collaborative learning.

\section{Discussion}

The objectives of this article were: 1) to present a map of the most relevant YouTube uses and practices applied by teens, and 2) to identify, describe, and analyse the most relevant metaphors of YouTube detected in teens' discourses. Regarding the first objective, the research team identified a series of emerging practices that led to five 
YouTube uses: radiophonic, televisual, social, productive and educative. Most of these uses are interwoven with the teens' everyday routines and the way they integrate the YouTube platform in various dimensions of their social life, such as their media practices, and the way they acquire knowledge and skills. Despite the civic potential of social media and the numerous studies on participatory culture (Jenkins, 2006), the research team did not detect that YouTube had a civic use, although we do not discard that this is a possibility. Nonetheless, Jenkins's (2006) proposal of civic engagement within participatory culture has been criticized by several authors for being too simple, optimistic and hard to apply at a macro-level (Couldry, 2011). Therefore, a more balanced understanding of participatory culture was applied to avoid the risk of misreading the political and economic interests that are part of the platform ecosystem, and which permeate teens' media practices but which do not correspond completely to a civic engagement. Regarding the second objective, the research team identified different analogies when teens put their YouTube uses and practices into discourse, leading to different types of metaphors. Most of these metaphors are part of a specific practice. Nonetheless, as certain practices are complex and involve different activities, these metaphors can switch back and forth depending on the practice performed and the use applied. That is, when a teen searches for certain content, YouTube is seen as a search engine, but depending on what the teen does with this content it can be seen as a companion or a MOOC, etc. Therefore, there is a long list of detected metaphors, which indicates that YouTube is a mutating platform that moves through different phases and conceptions due to the tensions between the actors (humans and non-humans) that inhabit and construct this digital space (Burgess \& Green, 2018). The metaphors identified reflect these ongoing mutations, reinforcing the idea that YouTube, like any other technology, can have different meanings and interpretations for various groups. 
However, as the practices change, so do the users' metaphors, and thus the scientific categories may need to be reshaped. The present research could therefore be expanded in different directions. It would be interesting to analyse the YouTube practices and uses of other social groups and compare them with those of teens. The analysis should also include how these social groups put YouTube into discourse, what metaphors they apply and how these change depending on their activities. Some research questions could be explored: What are adults doing with YouTube? Are adult YouTube practices reflected in the teens' uses and metaphors? What are the uncommon uses? If, as Martín-Barbero (1993) put it, "cultural competences” are important for defining the uses of media, those competences live "in 'memories' - in their narrative, gestures and sounds - and in the pool of cultural images that nourish the growth of different social protagonist identities such as women or youth" (p. 223). YouTube is a polyphonic technology that can generate different interpretations in the synchronic plane (i.e. for different social groups) but also, in the diachronic plane (i.e. in different moments of its evolution). It would also be interesting to explore in depth how platforms evolve in relation to the uses that were not initially planned for the platforms but rather were developed by the users themselves.

Finally, it is important to explore why many studies focus on the possible risks of social media use for teens and ignore the possible benefits. In many cases, these studies are based on technopanic discourses that pathologize teens' media and technology uses, and generate societal anxiety (Marwick, 2008). This research has opened a path to look beyond protection and prohibition because a precautious attitude may be a sign of competence, but it could also be a limiting fear (Pereira, Moura, Masanet, Taddeo, \& Tirocchi, 2018). The findings of the present article move away from this technophobia and show that social media platforms can also provide 
opportunities for acquiring transmedia skills and social abilities.

This work was supported by European Union's Horizon 2020 research and innovation programme: [Grant Number 645238].

\section{References}

Aran-Ramspott, S., Fedele, M., \& Tarragó, A. (2018). Youtubers' social functions and their influence on pre-adolescence. Comunicar, XXVI(57), 71-79. https://doi.org/10.3916/C57-2018-07

Barker, C. (2004). The SAGE Dictionary of Cultural Studies. London: Sage.

Bucher, T. (2018). Cleavage-Control: Stories of Algorithmic Culture and Power in the Case of YouTube "Reply Girls". In Z. Papacharissi (Ed.), A Networked Self and Platforms, Stories, Connections (pp.125-143). New York: Routledge.

Burgess, J., \& Green, J. (2018). Youtube: Online video and participatory culture (2nd ed.). Cambridge: Polity Press.

Carroll, R. L., Silbergleid, M., Beachum, C., Perry, S. Pluscht, P., \& Pescatore, M. (1993). Meanings of radio to teenagers in a niche-programming era. Journal of Broadcasting \& Eletronic Media, 37(2), 159-176.

Caron, C., Raby, R., Mitchell, C., Théwissen-LeBlanc, S., \& Prioletta, J. (2017). From concept to data: sleuthing social change-oriented youth voices on YouTube. Journal of Youth Studies, 20(1), 47-62.

Coombs, P. H., \& Ahmed, M. (1974). Attacking rural poverty: How non-formal education can help. Baltimore: Johns Hopkins University Press.

Couldry, N. (2012). Media, society, world: Social theory and digital media practice. Cambrige: Polity Press. 
Couldry, N. (2011). More sociology, more culture, more politics: Or, a modest proposal for a "convergence” studies. Cultural Studies, 25(4-5), 487-501. https://doi.org/10.1080/09502386.2011.600528

Doyle, G. (2016). Digitization and Changing Windowing Strategies in the Television Industry: Negotiating New Windows on the World. Television \& New Media, 17(7), 629-645.

Establés, M.-J., Guerrero-Pico, M., \& Contreras-Espinosa, R.-S. (2018). Gamers, writers and social media influencers: professionalisation processes among teenagers. Revista Latina de Comunicación Social, (74), 214-236. https://doi.org/10.4185/RLCS-2019-1328en

Fernández, J. L. (2018). Plataformas mediáticas: Elementos de análisis y diseño de nuevas experiencias [Media platforms: Elements of analysis and experience design]. Buenos Aires: Crujía.

García-Canclini, N. (2005). Hybrid Cultures: Strategies for Entering and Leaving Modernity. Minneapolis: University of Minnesota Press

Guerrero-Pico, M., Masanet, M.-J., \& Scolari, C. A. (2019). Toward a typology of young produsers: Teenagers' transmedia skills, media production, and narrative and aesthetic appreciation. New Media and Society, 21(2), 336-353. https://doi.org/10.1177/1461444818796470

Gutiérrez, M. (2008). Dispositivo radiofónico y vida cotidiana en los inicios de la radiodifusión [Radiophonic device and daily life in the beginning of broadcasting]. In J. L. Fernández (Ed.), La construcción de lo radiofónico [The radiophonic construction] (pp. 91-107). Buenos Aires: Crujía. 
Hui A., Schatzki T. R., \& Shove, E. (2017). Introduction. In A. Hui, T. R. Schaztki \& E. Shove. (Eds.), The Nexus of Practices: Connections, constellations, practitioners (pp.1-7). London and New York: Routledge.

Ito, M., Baumer, S., Bittanti, M., boyd, d., Cody, R., Herr-Stephenson, B., ... Tripp, L. (2010). Hanging Out, Messing Around, and Geeking Out: Kids Living and Learning with New Media. Cambridge, MA: The MIT Press.

Katz, E. (1980). Media events: The sense of occasion. Studies in Visual Communication, 6(3), 84-89.

Kim, J. (2012). The institutionalization of YouTube: From user-generated content to professionally generated content. Media, Culture \& Society, 34(1), 53-67.

Lakoff, G., \& Johnson, M. (1980). Metaphors We Live by. Chicago: University of Chicago Press.

Livingstone, S., \& Sefton-Green, J. (2016). The Class. Living and Learning in the Digital Age. Nueva York: NYU Press.

Masanet, M.-J., Guerrero-Pico, M., \& Establés, M.-J. (2019). From Digital Native to Digital Apprentice. A Case Study of the Transmedia Skills and Informal Learning Strategies of Adolescents in Spain. Learning, Media and Technology. https://doi.org/10.1080/17439884.2019.1641513

Marsick, V. J., \& Volpe, M. (1999). The Nature of and Need for Informal Learning. In V. J. Marsick \& M. Volpe (Eds.), Informal Learning on the Job, Advances in Developing Human Resources, No. 3 (pp.1-9). San Francisco: Berrett Koehler.

Martín-Barbero, J. (1993). Communication, Culture and Hegemony: From the Media to Mediations, London: Sage.

Marwick, A. E. (2008). To catch a predator? The MySpace moral panic. First Monday, 13(6), 1-21. 
McDonald, D. G. (1986). Generational aspects of television coviewing. Journal of Broadcasting \& Electronic Media, 30(1), 75-85.

Ortony, A. (1979). Metaphor and Thought. Cambridge, UK: Cambridge University Press.

Pereira, S., Moura, P., Masanet, M.-J., Taddeo, G., \& Tirocchi, S. (2018). Media uses and production practices: case study with teens from Portugal, Spain and Italy. Comunicación y Sociedad, (33), 89-114. https://doi.org/10.32870/cys.v0i33.7091

Pereira, S., Moura, P., \& Fillol, J. (2018). The YouTubers Phenomenon: What Makes YouTube Stars so Popular for Young People? Fonseca, Journal of Communication, (17), 107-123. https://doi.org/10.14201/fjc201817107123 THE

Pink, S., \& Morgan, J. (2013). Short-term ethnography: intense routes to knowing. Symbolic Interaction, 36(3), 351-361.

Pires, F. (2018). Connected co-viewing on Facebook: telenovela and the perception of media realism. Television and New Media, 19(7), 646-659. https://doi.org/10.1177/1527476417741672

Postill, J. (2010). Introduction: Theorising Media and Practice. In B. Bräuchler \& J. Postill (Eds.), Theorising Media and Practice (pp.1-34). New York, Oxford: Berghahn Books.

Reckwitz, A. (2002). Toward a theory of social practices a development in culturalist theorizing. European Journal of Social Theory, 5(2), 243-263.

Reimer, M., \& E. Camp (2008). Metaphor. In E. Lepore and B. C. Smith (eds.) The Oxford Handbook of Philosophy of Language (pp. 845-862). Oxford: Oxford University Press. Online version. doi: 10.1093/oxfordhb/9780199552238.003.0033 Schatzki, T. R. (1996). Social Practices: A Wittgensteinian Approach to Human Activity and the Social. New York: Cambridge University Press. 
Scolari, C. A. (Ed.). (2018). Teens, Media and Collaborative Cultures.

Exploiting Teens' Transmedia Skills in the Classroom. Barcelona: Transmedia Literacy H2020 Research and Innovation Action/Universitat Pompeu Fabra.

Scolari, C. A., \& Fraticelli, D. (2017). The case of the top Spanish YouTubers: Emerging media subjects and discourse practices in the new media ecology.

Convergence: The International Journal of Research into New Media Technologies, 25(3), 496-515. https://doi.org/10.1177/1354856517721807

Shove, E., Pantzar, M., \& Watson, M. (2012). The dynamics of social practice: Everyday life and how it changes. London, Thousand Oaks, New Delhi Singapore: Sage publications.

Steirer, G. (2014). The personal media collection in an era of connected viewing. In: J. Holt \& K Sanson (Eds), Connected Viewing: Selling, Streaming, \& Sharing Media in the Digital Era (pp. 79-96). New York; London: Routledge.

Street, B. V. (2014). Social Literacies: Critical Approaches to Literacy in Development, Ethnography and Education. London: Routledge.

Troldahl, V. C., \& Skolnik, R. (1968). The meanings people have for radio today. Journal of Broadcasting, 12(1), 57-67.

van Dijck, J. (2013). The Culture of Connectivity: A critical history of social media. Oxford: Oxford University Press.

Warde, A. (2005). Consumption and theories of practice. Journal of consumer culture, 5(2), 131-153.

YouTube (2019). YouTube for Press. Retreived from: https://www.youtube.com/intl/en-GB/yt/about/press/. 